\title{
Réseaux littéraires France-Québec (1900-1940), sous la direction de Denis Saint-Jacques
}

\section{Simona Rossi}

\section{(2) OpenEdition}

1 Journals

\section{Edizione digitale}

URL: http://journals.openedition.org/studifrancesi/33773

DOI: 10.4000/studifrancesi.33773

ISSN: 2421-5856

\section{Editore}

Rosenberg \& Sellier

\section{Edizione cartacea}

Data di pubblicazione: 1 décembre 2005

Paginazione: 683

ISSN: 0039-2944

\section{Notizia bibliografica digitale}

Simona Rossi, «Réseaux littéraires France-Québec (1900-1940), sous la direction de Denis Saint-

Jacques», Studi Francesi [Online], 147 (XLX | III) | 2005, online dal 30 novembre 2015, consultato il 18 avril 2021. URL: http://journals.openedition.org/studifrancesi/33773 ; DOI: https://doi.org/10.4000/ studifrancesi.33773

\section{Questo documento è stato generato automaticamente il 18 avril 2021.}

\section{(c) (1)}

Studi Francesi è distribuita con Licenza Creative Commons Attribuzione - Non commerciale - Non opere derivate 4.0 Internazionale. 


\title{
Réseaux littéraires France-Québec (1900-1940), sous la direction de Denis Saint-Jacques
}

\author{
Simona Rossi
}

\section{NOTIZIA}

"Études littéraires. Théories, analyses et débats», Réseaux littéraires France-Québec (1900-1940), sous la direction de Denis Saint-Jacques, vol. 36, n² 2, automne 2004, pp. 148.

1 Quest'ultimo numero di "Études littéraires" è il risultato di un lungo lavoro di ricerca sui rapporti intellettuali esistenti tra Francia e Québec condotto da Gérard Fabre e Denis Saint-Jacques, il curatore del volume. I saggi che lo compongono s'interrogano sull'influenza dei movimenti letterari francesi sulla letteratura quebecchese, ma non solo: a volte, infatti, la letteratura e i testi non sono sufficienti, servono personalità di rilievo che facciano da "passeurs", "des personnes qui servent de relais, qui conditionnent, qui garantissent, qui acculturent" (p. 8). È esattamente a queste persone e alle reti di scambio culturali che hanno saputo attivare che è dedicato questo insieme di lavori. Il periodo storico analizzato riguarda i quarant'anni che precedono la seconda guerra mondiale, quando la letteratura canadienne-française non appare particolarmente legata alle attività letterarie parigine: l'ipotesi è dunque che i contatti intellettuali tra francesi e canadesi si siano costruiti su altre basi. Quella mondana, ad esempio, come spiega Chantal Savoie aprendo la sezione études: il suo saggio si occupa dell'Esposizione Universale di Parigi nel 1900, la quale prevedeva, tra le diverse attività, anche la riunione del Consiglio Internazionale delle donne. In qualità di delegate del Conseil National des Femmes du Canada (CNFC), vi presero parte alcune donne canadesi. Tale partecipazione rappresentò per loro una vera e propria svolta: allargarono infatti i loro orizzonti di lettura, strinsero legami con donne influenti dell'epoca, frequentarono i salotti parigini e una volta rientrate in patria, fondarono riviste letterarie e nuove associazioni, mostrandosi molto più determinate e disponibili a rapporti di 
collaborazione con le "colleghe" francesi. Chantal Savoie ha analizzato con attenzione i diari e le corrispondenze intime delle delegate in questione e il cambiamento che si nota dal periodo precedente all'esposizione a quello successivo è davvero radicale, chiaramente sostenuto e alimentato dalla vivacità intellettuale del femminismo francese.

2 Altrettanto radicale è la spaccatura descritta da Pierre Rajotte nel suo saggio tra coloro che, nel periodo tra le due guerre, consideravano in maniera positiva il fatto che gli scrittori canadesi soggiornassero spesso a Parigi e coloro che, invece, pensavano che tali esperienze uccidessero talento e autenticità quebecchesi. Rajotte sottolinea il fatto che lo spostamento, seppur temporaneo, di autori canadesi-francesi in Francia, provocava all'epoca forti dibattiti: c'era chi lo giudicava un importante stimolo alla creatività e chi si preoccupava dell'eventuale contaminazione che poteva produrre, ma nessuno lo considerava di fatto ininfluente. Questo è un chiaro indice di quanto l'aurea culturale della Francia influenzasse l'opinione pubblica quebecchese. Gli ultimi due saggi che compongono la sezione portano rispettivamente la firma di Michel Lacroix e Gwénaëlle Lucas e approfondiscono l'argomento introdotto da Pierre Rajotte. Il primo si occupa di coloro che negli anni Venti erano definiti exotiques a causa della loro propensione a trascorrere lunghi periodi all'estero e in particolare a Parigi, dove si diffuse l'idea di una sorta di "latinità" canadienne-française che univa quebecchesi, francesi e sud-americani in un gruppo cosmopolita avente in comune sia l'ideologia culturale che quella politica, molto vicina al fascismo nascente. Completamente dall'altra parte della barricata è invece Gwénaëlle Lucas, che si interessa a coloro che dimostravano di non trovare nessun feeling con la produzione letteraria francese e con la sua egemonia culturale. Il saggio verte in particolare sulla figura di Marie Le Franc, una scrittrice di origine francese ma che scriveva anche in inglese, la quale si adoperò in tutti i modi per creare una rete culturale locale, fatta di autori provinciali detti régionalistes, il cui valore fosse riconosciuto anche dalla Francia.

3 La seconda sezione della rivista, analyses, conta due saggi: il primo, di Marie-Hélène Larochelle, è una rilettura del romanzo Le nez qui voque di Réjean Ducharme a proposito del tema del malinteso; il secondo, invece, a cura di Frank Wagner, è un rapido percorso critico che va dallo strutturalismo al post-strutturalismo. Débat, infine, comprende uno scambio di lettere tra Claude La Charité e Martin Robitaille sulla retorica epistolare di Rabelais, argomento centrale all'interno del recente libro di Claude La Charité, $L a$ rhétorique épistolaire de Rabelais, recensito da Robitaille. Originale e ricco di spunti interessanti per eventuali approfondimenti, l'ultimo numero di "Études littéraires" rappresenta senza dubbio una lettura stimolante. 